\title{
How to run a successful and educational basketball camp
}

\author{
Brooke LeMar ${ }^{1}$ \\ Joe Deutsch ${ }^{2}$
}

\begin{abstract}
Camps are a great introduction to the sport of basketball for children. Universities and colleges usually offer different types of camps, typically during the summer months. Depending on the skill and maturity level of the player, basketball camps can serve a variety of purposes. Some popular types of camps include offensive skills, shooting, team, and youth camps. Regardless of the camp that is chosen, children need to have goals set for themselves before, during, and after to enhance the benefits. Each camper should have the opportunity to grow and develop as a basketball player as well as an individual. Running a successful camp is not only rewarding for the coaches, but for the players and campers too, which ultimately leads to the campers choosing to come back every year.
\end{abstract}

Keywords: Basketball Camp; Education; Teaching; Coaching; Youth Sport

Most adult that works extensively with children will say that a well-rounded student needs to learn to communicate and work collaboratively with their peers, needs to be physically active to promote healthy growth, and needs to be exposed to the principles for a healthy adult lifestyle. These principles are all important in order to navigate their way through an increasingly complex world (Gould \& Carson, 2008). Basketball, a team sport that requires teamwork, physical activity, and on court collaboration, is an extremely popular sport in the United States and throughout the world. Children already play basketball for both recreational and competitive purposes at many different levels (Sports Camp Connection, 2014). Not only does basketball enhance a child's physical ability, it also builds his or her social communication and collaboration skills. It is important for children of

\footnotetext{
${ }^{1}$ Graduate Assistant, North Dakota State University, Health, Nutrition, \& Exercise Sciences, Brooke.LeMar@ndsu.edu 2 Associate Professor of Physical Education, North Dakota State University, Health, Nutrition, \& Exercise Sciences, Joe.Deutsch@ndsu.edu
} 
LeMar, B., Deutsch, J., (2015). How to run a successful and educational basketball camp. International Journal of Human Sciences, 12(1), 1182-1188. doi: $10.14687 /$ ijhs.v12i1.3241

all ages to get involved with an activity like basketball in order to be physically active and to learn how to work collaboratively with others (Prichard \& Deutsch, 2013).

Camps are a great introduction to the sport of basketball for children. Universities and colleges usually offer different types of camps, typically during the summer months. Depending on the skill and maturity level of the player, basketball camps can serve a variety of purposes. Some popular types of camps include offensive skills, shooting, team, and youth camps. Regardless of the camp that is chosen, children need to have goals set for themselves before, during, and after to enhance the benefits (Kauffman \& Deutsch, 2010).

An offensive skills camp can be for a variety of age groups and should be focused on developing each player's specific abilities. Depending on the age and the level of the camper, a skills camp can be used for recruiting purposes. The athletes can go to camp and be assessed by the college coaches who run the camp. A shooting camp can also have a variety of age groups and is focused solely on developing the proper shooting mechanics. Another popular type of camp is a team camp. Team camps are run like a tournament and consist of high school or Amateur Athletic Union (AAU) teams. Team camps may have some instruction as well, but mainly serve the purpose of pulling teams together to compete and hear words of wisdom from the University's head coach. The coaches running the camp can schedule a time during camp when all the teams learn some of the drills that college teams perform. For example, during a recent Division I school's team camp, there was an hour where the collegiate basketball team demonstrated a partial skill. And last but not least, youth camps should serve to help teach children the game, develop individual skills, and to create a positive experience. It is vital for children to develop in all aspects of well-being, and a youth camp can do just that (Luce \& Deutsch 2014).

The following is designed to assist coaches in developing a successful basketball camp. It is important to follow the proper steps to run a high quality, well organized, safe, and fun camp (Bjorling \& Deutsch, 2010). The very first step is to decide what type of camp you want to have. Many types of camps require targeting specific age groups and different equipment. In addition, both facilities and staff may need to be adjusted based on the demand.

The second step is to find a facility. For college institutions, it is usually easy to get a facility because they can use their own gymnasiums. Sometimes conflicts may occur with other school activities, or the gym space is too small, so the school recreation center may be another option for some camps. Once a facility is determined, it is important to set aside a time period for the camp that works with gym availability and camper availability. In addition, gym availability can affect camp length, which is important when dealing with steps three and four. 
LeMar, B., Deutsch, J., (2015). How to run a successful and educational basketball camp. International Journal of Human Sciences, 12(1), 1182-1188. doi: 10.14687/ijhs.v12i1.3241

The third step is to determine the costs of running the camp. Some common expenses are the facility, camp t-shirts, camp basketballs, staffing, renting dorms for overnight campers, food, and insurance (Dickhudt, 2014). Based on the type of camp, some items in this list aren't necessary. For example, some schools don't have as much funding or resources as other schools, so they might have to limit what type of camp they can run or how many people are allowed in the camp, in order for the camp to be economically efficient.

The fourth step is to organize and plan the basketball camp. An effective plan should be determined based on camp type: youth camp, offensive skills camp, shooting camp, or team camp. Promoting the camp is the next step for planning. After advertising the camp a detailed schedule of the actual camp should be determined. The schedule will include an introduction, a warm up, a variety of drills, and even games. Appropriate time ranges should be included on the schedule to cover all planned drills. This means that each skill will be given enough time so that the material will stick with the camper. Another important part of planning is to determine who is doing what for the camp. All staff members should be engaged and have a role in running the camp. In case something goes wrong, the staff should be prepared on how to handle the situation. The athletic training staff will need to be CPR and First Aid certified. The rest of the staff will go through a protocol handbook prior to hosting the camp. Some camps may also require the staff to go through a training program (Ellenburger \& Deutsch, 2014).

The following is a detailed account on how to specifically run a youth basketball camp. The age of the campers can range from 5-11 years old, or first grade through fifth grade. During a skills camp, the coaches will teach skills from all positions in basketball and will incorporate different drills to breakdown certain techniques, such as the box-out or the crossover. The camp will also teach the basic fundamentals of offense and defense and can last anywhere from 1-3 days. This camp is usually split up into two groups, first, second, and third graders are a group, and fourth and fifth graders are a group. They will all participate in the same drills, but at different times in separate groups as there is an understanding that the younger campers will probably need more attention, while the other campers can receive more advanced instruction.

When setting up a youth camp at a University, the coaches typically have access to their own facilities without any issues. A camp like this can have up to 100 campers depending on how much space that is available. Most of the campers are usually local, but there are also those who travel quite a distance. If the camp lasts more than one day, campers can stay in the dorms. Resident halls are not only for the campers who live far away, but any camper who registers for this camp can use the dorms. Most of the time the kids want to stay in them for the experience. 
LeMar, B., Deutsch, J., (2015). How to run a successful and educational basketball camp. International Journal of Human Sciences, 12(1), 1182-1188. doi: 10.14687/ijhs.v12i1.3241

When determining the costs of the camp it is important to look at how many campers there will be. Some costs of a youth camp will include advertising, room and board, camp shirts, staff pay, and insurance (Dickhudt, 2014). The staff is usually made up of the coaches, college basketball players, managers, and trainers. When pricing the camp, keep it reasonable so the campers can afford it and will be willing to come, at the same time enough to make a profit.

The first part of organizing the camp is to promote it. Handing out flyers, brochures at local schools, posting a notification on social media and the school website, and sending emails to alumni is a good way to promote the camp (Christianson, Breker, \& Deutsch, 2012). The advertising should be done well in advance. Emails, websites, and other social media networks should advertise the dates of the camps at least a month before the first day of camp. Planning the actual camp requires communication with the entire staff. It is important to communicate with the athletic director about the camp. A 3-day camp usually starts in the evening of day one and lasts approximately 3-4 hours. After the first day, overnight campers will eat dinner and then move over to the dorms. Commuter campers go home and meet at the gym in the morning for the next day of camp. It is the staff's responsibility to not lose anyone and to make sure the kids have the appropriate supervision. The second day of camp is a full day of activities. It usually starts at 9AM and finishes at 9PM. Breakfast for the overnight campers starts at 8AM in the cafeteria. There is a lunch and dinner break for all the campers to keep them fueled for their long day. These breaks last anywhere from 1-2 hours. The third day of camp starts early in the morning and goes only a few hours. The last day is usually the camper's favorite because they get camp shirts, camp basketballs, and the player's autographs. There is also an awards ceremony for winners of the competitions that were held during camp.

During these three days different drills and activities will be taught. Here is an example schedule of a three-day youth camp:

\title{
Basketball Youth Skills Camp
}

\author{
$\underline{\text { Day } 1}$ \\ 4:00 pm Coaches Meeting \\ 5:00 pm Camp Registration \\ 6:00 pm Annual Camp Begins/ Introductions \\ 6:10 pm Warm Up \& Divide in Groups \\ 6:30 pm Ball Handling Drills and Games \\ 7:00 pm Battle Dribble Competitions \\ 7:15 pm Teach Jump Stops and Pivots \\ 7:30 pm Shooting Clinic: teach cues (hand in cookie jar on follow through, ball on fingertips) \\ 8:00 pm Water \\ 8:05pm Miss Pac Man Game (dodging dribbling game)
}


8:30 pm "Shootout" - shooting competitions

9:10 pm CampEnds

Overnight Campers

9:30 pm Walk to Dorms

\section{Day 2}

8:00 am Walk from Dorm to Cafeteria (overnight campers only)

8:30 am Walk Cafeteria to Dorm (overnight campers only)

8:45 am Walk Dorm to Camp (overnight campers only)

9:00 am Camp Starts (All campers meet at gym)

11:30 am Break for Lunch Walk to Cafeteria

1:15 pm Walk to Camp from Cafeteria or Dorms

1:30 pm Roll Call

1:40 pm Warm Up

1:50 pm Stations (10 min each)

1. Shooting

2. Lay-ups

3. Dribbling

4. $10 \mathrm{n} 1$

5. Rebounding

6. Defense

2:50 pm Water Break

2:55 pm Relay Games

3:15 pmTriple Threat

1. Teach from baseline

2. Jab steps, jump stops, pivots

3:45 pm Breakdown Passing \& Catching (bounce, chest, skip passes)

4:10 pm Water Break

4:15 pm GAMES

1. Red light green light

2. Lightning/Knockout

3. 7-Up

4:45pm Dismiss to Cafeteria

5:30pm Walk to Dorm

6:15 pm Walk to Camp

6:30 pm Roll Call

6:35 pm Warm Up

6:45 pm Around the World Shooting (spots around the key)

7:00 pm Defensive Breakdowns (6 stations)

7:55 pm Water

8:00 pm Break into teams, assign team to a coach

1. Mini practice

2. 5 0n 5 games

9:00 pm Dismiss Camp

Overnight Campers

9:30 pm Walk to Dorm

\section{Day 3}

8:00 am Walk from Dorm to Cafeteria

8:45 am Walk Dorm/Cafeteria to Camp 
LeMar, B., Deutsch, J., (2015). How to run a successful and educational basketball camp. International Journal of Human Sciences, 12(1), 1182-1188. doi: 10.14687/ijhs.v12i1.3241

9:00 am Camp Starts

9:10am Break into teams

1. One fun fact about each camper

2. Play a game to help remember names

9:30am Warm Up

9:45am Passing Drills

10:00am Defensive Drills (stance, lane slides, communication)

10:30am Lightning Games (shooting competition)

10:45am Chain Link Games (non-elimination tag)

11:00am Team Building Games

11:30am Break for Lunch

1:30 pm Roll Call

$1: 45 \mathrm{pm}$ Rebounding

2:00pm Shooting Drills

2:30 pm Dismiss Camp!

1. Sign autographs/basketballs/camp shirts

2. Take pictures with campers

After the camp is all put together, the final step is to run the actual camp as smoothly as possible. The camp should be a fun and safe learning environment. A check in and registration area should be set up and easy to find. Any policies should be noted here so the parents and campers know what is or isn't allowed. Each staff should have their own station ready to go, and should be engaged at all times. A staff member should never leave a camper unsupervised. During camp hours the children are the staff's responsibility, especially the overnight campers. There will be several supervisors who stay in the same dorm building as the campers for safety reasons. There should be room checks to ensure that all the campers are in their rooms and safe during sleeping hours. Also, the supervisors are there to respond if any type of emergency were to occur. Parents sign waivers during check-in for any liability issues. It is important for each camp to have insurance for any accident that may occur (Dickhudt, 2014).

Not all youth camps are the same but they all require similar and extensive preparation. They require proper facilities, stable finances, and an organized plan. Youth camps typically focus on enjoyment and learning the fundamentals. It is important that the children have a positive experience when participating in youth basketball camps. Look for easy ways to enhance the enjoyment and excitement of the campers, such as the use of music whenever possible (Deutsch \& Hetland, 2012). Each camper should have the opportunity to grow and develop as a basketball player as well as an individual. Running a successful camp is not only rewarding for the coaches, but for the players and campers too, which ultimately leads to the campers choosing to come back every year. 
LeMar, B., Deutsch, J., (2015). How to run a successful and educational basketball camp. International Journal of Human Sciences, 12(1), 1182-1188. doi: 10.14687/ijhs.v12i1.3241

\section{References}

Bjorling, S. \& Deutsch, J. (2010). How to run a baseball hitting camp in a small town market, Journal of Youth Sports, 6(1), 3-9.

Christianson, N., Breker, M., \& Deutsch, J. (2012). How to run a soccer camp: For adolescents (Age 6-14), Journal of Youth Sports, 7(1), 13-14.

Deutsch, J. \& Hetland, K. (2012). The impact of music on pacer test performance, enjoyment, and work-load, Asian Journal for Physical Education \& Recreation, 18(1), 6-14.

Dickhudt, K. (personal communication, December 10, 2014).

Ellenburger, R. \& Deutsch, J. (2014). How to run a football camp for youth, Journal of Youth Sports, 7(2), 9-19.

Gould, D \& Carson, S. (2008). Life skills development through sport: current status and future directions, International Review of Sport and Exercise Psychology, 1(1), 58-78.

Kauffman, J. \& Deutsch, J. (2010). Successful goal setting in basketball: Which areas are important?, Missouri Journal of Health, Physical Education, Recreation, and Dance, 20, 44-48.

Luce, K. \& Deutsch, J. (2014). How to run a soccer academy, Journal of Youth Sports, 7(2), 9-19.

Prichard, A. \& Deutsch, J. (2013). The effects of motivational climate on students in physical education classes, Global Journal of Health and Physical Education Pedagogy, 2(2), 103-110.

Sports Camp Connection. (2014). Basketball camps for youths in your area. Retrieveed from http://www.sportscampconnection.com/sport/basketball-camps 